University of Wollongong

Research Online

Faculty of Social Sciences - Papers (Archive) Faculty of Arts, Social Sciences \& Humanities

$1-1-2018$

Conceptualising technology practice in education using Bourdieu's sociology

Karley A. Beckman

University of Wollongong, karleymc@uow.edu.au

Tiffani L. Apps

University of Wollongong, tiffani@uow.edu.au

Sue Bennett

University of Wollongong, sbennett@uow.edu.au

Lori Lockyer

University of Technology, lori.lockyer@gmail.com

Follow this and additional works at: https://ro.uow.edu.au/sspapers

Part of the Education Commons, and the Social and Behavioral Sciences Commons

Research Online is the open access institutional repository for the University of Wollongong. For further information contact the UOW Library: research-pubs@uow.edu.au 


\title{
Conceptualising technology practice in education using Bourdieu's sociology
}

\author{
Abstract \\ Evidence from large-scale studies of primary and secondary students' technology practices at school over \\ the last decade show disparities in student practices and suggest that schools need to do more to cater \\ for all students. Research that explores the influence of social and cultural factors may be useful for \\ understanding such inequality in student practice. Bourdieu's theory of practice [(1977). Outline of a \\ Theory of Practice. London: Cambridge University Press] is proposed as an example of a sociological \\ theory that can be adopted in educational technology research to move towards understanding the wider \\ complexities of technology practice. To encourage discourse and application of Bourdieu's sociology in \\ the field of educational technology research, this paper provides an introduction to the theory, a review of \\ its application in research of primary and secondary students' technology practice and relevant \\ conceptual work. The paper presents a conceptual framework based on Bourdieu's theory that has been \\ developed through two recent studies, and review of empirical and conceptual works and invites its \\ application in future research so that it can be critiqued and further developed.

\section{Keywords} \\ conceptualising, practice, bourdieu's, technology, education, sociology \\ Disciplines \\ Education | Social and Behavioral Sciences \\ Publication Details \\ Beckman, K., Apps, T., Bennett, S. \& Lockyer, L. (2018). Conceptualising technology practice in education \\ using Bourdieu's sociology. Learning, Media and Technology, 43 (2), 197-210.
}




\title{
Conceptualising technology practice in education using Bourdieu's sociology
}

\author{
Karley Beckman ${ }^{\mathrm{a} *}$, Tiffani Apps ${ }^{\mathrm{a}}$, Sue Bennett ${ }^{\mathrm{a}}$ and Lori Lockyer ${ }^{\mathrm{b}}$ \\ ${ }^{\text {a }}$ School of Education, Faculty of Social Sciences, University of Wollongong, \\ Australia \\ ${ }^{\mathrm{b}}$ Faculty of Arts and Social Sciences, University of Technology Sydney, Australia \\ *Email: karley_beckman@uow.edu.au
}

\begin{abstract}
Evidence from large-scale studies of primary and secondary students' technology practices at school over the last decade show disparities in student practices and suggest that schools need to do more to cater for all students. Research that explores the influence of social and cultural factors may be useful for understanding such inequality in student practice. Bourdieu's theory of practice [(1977). Outline of a Theory of Practice. London: Cambridge University Press] is proposed as an example of a sociological theory that can be adopted in educational technology research to move towards understanding the wider complexities of technology practice. To encourage discourse and application of Bourdieu's sociology in the field of educational technology research, this paper provides an introduction to the theory, a review of its application in research of primary and secondary students' technology practice and relevant conceptual work. The paper presents a conceptual framework based on Bourdieu's theory that has been developed through two recent studies, and review of empirical and conceptual works and invites its application in future research so that it can be critiqued and further developed.
\end{abstract}

Keywords Bourdieu's theory of practice; sociology; educational technology; digital; school student

To cite this article: Karley Beckman, Tiffani Apps, Sue Bennett \& Lori Lockyer (2018): Conceptualising technology practice in education using Bourdieu's sociology, Learning, Media and Technology, DOI: 10.1080/17439884.2018.1462205

To link to this article: https://doi.org/10.1080/17439884.2018.1462205 
Much significance is placed on the role of technology in education to foster skills and competencies that prepare students for their digital futures. Yet, a growing body of research details disparities in primary and secondary school students' technology practices, skills, and knowledge associated with a range of social and cultural factors (OECD 2010). Evidence from large scale studies of developed nations over the last 10 years show that such disparities have remained consistent and suggest that schools need to do more to cater for all students (ACARA 2015; OECD 2011). In order to realise such an agenda, it is important to first understand the diversity with which students experience technology, paying particular attention to the role of available social and cultural resources.

Despite an extensive body of educational technology research, there is limited research that provides a detailed understanding of school students' technology practice in context. Much of the empirical research to date has focused on the perpetual introduction of each new technology in schools and society, and the effects of these various technological artefacts on learning. This work provides important evidence of the effectiveness of using specific technologies to support specific learning processes and outcomes. However, what is missing is a broader understanding of technology practice in education (Bennett and Oliver 2011; Oliver 2016). Research that conceptualises digital technologies as social tools, encompassing the artefact, its use and its context, will help provide an understanding of the interrelations between technology practice, students, their relationships, histories and surroundings.

Drawing on practice theory, practice, more generally, is seen as a social phenomenon. Practice is more than describing what people do or use, but acknowledges the act as embedded in the context as a meaning-making, structuring activity (Nicolini 2012). Bourdieu was a key practice theorist, and thus drawing on Bourdieu's notion of practice, technology practice is defined as more than the use of the technology, but also encompasses the social and cultural relations, systems and structures, and the meaning the practice has in the individual's life. Technology practices do not exist without the individuals who use them and the contexts in which they are used; thus, "they cannot be studied in isolation from society or from one another" (Sterne 2003, $385)$. 
A growing body of research proposes that a theoretically grounded definition of technology and technology practice may offer a means to extend research agendas beyond effects of technology and the immediate practical implications (Oliver 2016; Selwyn 2010). Moving toward an understanding of technology practice in and across contexts may uncover digital inequalities and how they may be reproduced or transformed. Research in the field of educational technology would benefit from a sociological framing that pays attention to the understandings of learners and considers the social and cultural milieu of technology practice (Erstad 2012; Selwyn 2012). However, despite application in sociology, science and technology disciplines to frame technologies as social (Ignatow and Robinson 2017), sociological studies are relatively rare in the field of educational technology (Oliver 2013; Selwyn 2012). The promise of sociological research in various disciplines, including education more generally, and the small, yet growing movement in educational technology drawing on the work of Cuban (2001), Latour (2005) and Fenwick (2015), has motivated calls for a more critical approach to the investigation of technologies for learning that extends beyond immediate practicalities (Bennett and Oliver 2011; Kerr 1996; Selwyn 2010). The inclusion of these types of studies within the literature can address questions of how individual, physical, social and cultural structures interrelate to shape technology practice.

Bourdieu's theory of practice (1977) is one example of sociological theory that has been applied in other areas of educational research to explore the interrelations between students and the physical, social and cultural aspects of school and homes and how these shape student practice (discussed below). Bourdieu's sociological theory prescribes a research focus broader than that of the phenomena or individuals under investigation (Reay 2004). The theoretical constructs of the theory, field, habitus and capital provide a means with which to understand the relational nature of social structures and individual practice (Nash 1990), thus yielding "insights and understanding not readily visible in other approaches" (Mills and Gale 2007, 2). This is particularly relevant to the conceptualisation of educational technologies as social tools. 
To encourage discourse and application of Bourdieu's sociology in the field of educational technology research, this paper offers a conceptual application of the theory of practice to school students' technology practices. Firstly, this paper provides an introduction to the theory of practice, in some detail particularly for readers less familiar with the key constructs. This is followed by a review of studies of primary and secondary school students' technology practices that use Bourdieu's constructs highlighting the contribution and limitations of the theory in educational technology research. Lastly, the paper presents a conceptual framework based on Bourdieu's theory that has been developed through two recent studies and invites its application in future research so that it can be critiqued and further developed.

\section{Bourdieu's theory of practice}

Bourdieu's theory of practice is a science of human practice (Wacquant 1998). His theoretical constructs serve as theoretical and methodological tools for systematic analysis of social phenomena. The theory of practice perceives action as taking place within a social world, but also perceives the social world as being internalised within the individual (Bourdieu 1990a). More specifically, the theory of practice considers practice as more than actions of an individual; practices also encompass social and cultural relations, systems and structures, and the meaning the practice holds in the individual's life. The dualistic relationship between the individual (embodied) and the social world (objective) is intrinsic in all Bourdieu's theoretical constructs.

Formally, Bourdieu summarised practices as a product of the relations between field, habitus and capital: '[(habitus)(capital)] + field = practice' (Bourdieu 1984, 95). According to Bourdieu, an individual's practice is both structured by their habitus and capital within the field occupied, and structuring, in that they shape future practice. Field, habitus and capital are relational constructs that do not act, nor can they be understood, independently.

Before discussing each of these concepts, it is important to note that Bourdieu constantly warned to "beware of words" and the accumulated, value-laden nature of their social construction (Bourdieu and Wacquant 1989, 54). Accordingly, Bourdieu adopted purposefully selected language in which to communicate his concepts in an attempt to escape common-sense assumptions. However, this has resulted in much 
criticism of his arduous language and extensive explanations (Jenkins 1992). The following section attempts a concise explanation of Bourdieu's key concepts intended to provide an accessible introduction to his theory for educational technology researchers.

\section{Field}

Bourdieu asserted that to understand people and their practices, it was necessary to understand them in light of examination of the social space (Bourdieu 2005). It is with this social orientation that Bourdieu's concept of field was founded. Fields are social domains rather than physical spaces, and so defined by the individuals who occupy those domains; that is, their "networks of social relations, structured systems of social positions" (Everett 2002, 60). "Each field has its own distinctive logic of practice" (Grenfell 2012, 68), or accepted way of behaving. Participants in a field share common beliefs, an adherence to which determines one's membership of the field (Bourdieu 1990b).

An individual's world is comprised of many fields, which they traverse as they go about their lives. The limits of each field are bounded by the effects of the field; thus, a field's boundaries exist where the effects of the field cease (Bourdieu and Wacquant 1992). For example, school students occupy a number of social fields, including the school field. While schools are physical locations, they are defined by the social relations, systems (e.g., rules and policies) and positions (e.g., teacher as authority). Students' homes, too, are physical spaces, but also social spaces defined by the family members and beliefs of the family social group. Increasingly, students occupy online fields, defined by the systems, members and positions of those who occupy the digital space and distinct from the physical location.

\section{Habitus}

Habitus is an individual's "history turned into nature" (Bourdieu 1977, 78). Habitus is the internalisation or embodiment of one's history, encompassing all circumstances and experiences that shape the individual's way of being and acting within and perceiving the social world (Bourdieu and Wacquant 1992). This is not to say that one's actions are determined by habitus, but rather that habitus shapes an individual's 
disposition toward ways of being, acting and perceiving. As habitus is shaped by an individual's experiences and circumstances, which are constantly changing, habitus too evolves because it is constantly subject to experiences that either reproduce or transform it (Bourdieu and Wacquant 1992).

Schools are fields in which students spend a significant amount of time and thus a significant field in shaping (reproducing or transforming) the habitus of its members. Bourdieu theorised schools as a field whose purpose was to socialise students by preparing them for working society (Swartz 1997). Moreover, emphasising "that schools teach students particular things and socialize them in particular ways" (Grenfell 2009, 188). Students' practices within a school field are shaped by their varied habitus (broader experiences and circumstances) meaning that students perceive and engage in experiences differently. Bourdieu elaborated: "the habitus acquired in the family underlies the structuring of school experiences... and the habitus transformed by schooling, itself diversified, in turn underlies the structuring of all subsequent experiences... and so on, from restructuring to restructuring" $(1977,87)$. For example, a student whose family encourages the use of technology for learning in the home may positively perceive similar uses at school and succeed, reinforcing this type of use of technology in both school and home fields, perhaps extending application of these practices in their personal interests or hobbies. Conversely, a student whose family uses technologies predominantly for social or leisurely uses, may perceive technology practices in the school field as unfamiliar, difficult or irrelevant, thus may be reluctant or require additional support. Members of a field generally share common beliefs and a feel for the game (Bourdieu 1990b), and thus two such students may feel a sense of belonging or being an outsider.

\section{Capital}

An individual's ability to succeed or manoeuvre in a field (i.e. their position in the field) is determined by their capital. Capital refers to assets that may include cultural and material goods and wealth that are derived through developing and maintaining social relationships, networks, skills and knowledge. The value of capital is determined by the field through recognition by others (Bourdieu 1990a). Thus, an individual's capital may vary in value across fields. For example, a student's skills 
and knowledge of online gaming, which assure powerful status in an online gaming field, may have little or no value within the school field.

There are a number of forms of capital (Bourdieu 1986). Economic, cultural and social capital are some of the most documented. Economic capital is "monetary and material wealth, commodities, and physical resources" (Everett 2002, 62) that are "immediately and directly convertible into money" (Bourdieu 1986, 243). According to Bourdieu, all other forms of capital are derivative of economic capital (Bourdieu 1986). For example, the concept of cultural capital was developed through empirical work investigating students' varied scholastic achievements (Bourdieu 1986). Variations in students' achievements were found not to result from their biological aptitude but rather from their cultural capital as determined by their social class. Cultural capital includes knowledge, skills, taste, lifestyle and qualifications, which may be embodied, objectified or institutionalised (Bourdieu 1986). Embodied capital is culture internalised by individuals (and into their habitus); for example, manifest in their taste, poise or accent. Objectified cultural capital is the objectification of cultural capital in material objects, but only inasmuch as an individual's ability to appropriate it into embodied capital (Bourdieu 1986). For example, a student may have access to a computer in their home, but this equipment is only considered objectified cultural capital if the student appropriates its use into the development of their own technological skills, knowledge or taste (cultural capital). Institutionalised capital relates to academic qualifications, which bestow cultural competence upon the individual (Bourdieu 1986). For example, completing a technology elective subject at school provides a school student with a level of specialist qualification. Social capital refers to "useful relationships that can secure material or symbolic profits" for the individual (Bourdieu 1986, 249). An individual's social capital is determined by the size or number of networks, the capital that the members of the network possess and confer, and the individual's ability to derive benefit from these networks of connections (Bourdieu 1986). For example, a student whose parents work with technology and engage with technology for both work and leisure at home, may derive benefit from the home network in developing their own technology practice.

\section{Bourdieu, education and social inequality}


Bourdieu's contribution to the sociology of education was based on his professional experiences in the French education system, during which he theorised education as an institution of cultural domination and reproduction of social class structures. Specifically, educational institutions confer the knowledge and skills of the dominant classes, and in turn legitimise these as scholastic aptitude of students within these social classes (Bourdieu 1984). Educational researchers and commentators have critically reviewed Bourdieu's theory of practice for its relevance to contemporary educational research (Grenfell and James 1998; Mills and Gale 2007; Nash 1990; Reay 2004; Robbins 2004). Despite criticisms, many of which stem from Bourdieu's ostensibly complex language and writing, his theory of practice is regarded as offering researchers a means to consider broader social aspects of education, uncovering abstruse aspects that are often overlooked or presumed.

The theory of practice places attention on the subtle, obscure or hidden structures and systems within education, including student social inequalities, the educational field of power and the reproductive hierarchy and structure of educational institutions (Mills 2008; Mills and Gale 2007). Bourdieu wrote extensively about the reproductive nature of educational fields. His analyses of the French education system introduced the notion of symbolic violence, through which culture is imposed upon groups or classes in such a way that it is experienced as legitimate (Schubert 2012). Schools and teachers act to impose symbolic violence unknowingly through pedagogic action that reproduces the dominant culture while also reproducing the power relations that underwrite its own operation (Webb et al. 2002). In practice, this occurs as education systems are designed to transmit dominant cultural capital. Thus, students who come from homes laden in this capital are at an advantage at the outset. For students who do not experience this cultural capital at home, achieving the same level of educational achievement is more difficult. In this way, the theory of practice provides researchers with conceptual and methodological tools for uncovering the reproductive nature of schooling that works to reinforce social inequalities.

In this way, educational research has taken up Bourdieu's theory, particularly his concept of capital, to highlight student social inequalities and the social structures of the school field and the impacts upon students' ability to "play the game" or succeed in school (Bok 2010; DiMaggio 1982; Mills and Gale 2010). Few educational studies 
have employed the more complex and contested concept of habitus. One example is a study of a youth education program that examined its impact upon students' and the transformative potential upon students' habitus (McNamara Horvat and Davis 2011). Qualitative research has also demonstrated value examining cultural capital together with habitus to investigate gender, school success and academic achievement (Dumais 2002; Gaddis 2013). Overall, the application of Bourdieu's concepts in education illuminates social inequalities and why they persist or potential for transformation within our schooling systems.

\section{Bourdieu's sociology in educational technology research}

The application of Bourdieu's theory of practice offers educational technology research a tool to recognise the differing technology experiences that contribute to digital inequality, while highlighting the problematic nature of policy and curriculum that view technology as a socially, culturally and politically neutral vehicle for the simple acquisition of meritocratic outcomes. However, despite a number of proposals and calls to action, the application of his concepts in educational technology research has been modest (Grenfell 2009; Robbins 2004; Selwyn 2004, 2012).

In this section, we present a review of empirical studies that have used Bourdieu's theory of practice to investigate primary and secondary school students' technology practice. The review of these studies will consider the application of the theory, as well as an analysis of the contribution and limitations of the theoretical framing. The 16 studies reviewed in this paper were retrieved through an ongoing literature search of empirical studies. The search criteria, developed across two doctoral studies, focussed on peer reviewed empirical studies which examine primary and secondary students' technology practice and demonstrate evidence of application of Bourdieu's theoretical constructs to technology practice in the methodology and/or analysis of the research findings (see Apps 2015; Beckman 2015). More specifically, studies included met the follow criteria:

1. Published in a peer-reviewed journal.

2. Present empirical research. This criterion was applied to ensure claims made in the studies were supported by data and thus exclude conceptual work, such as Selwyn (2004) and Kvansy and Truex (2000), whose contribution will be discussed later in the paper. 
3. Examines primary or secondary school students' technology practices.

Bourdieu's sociology is particularly useful in understanding the structures and relations that shape practices across diverse backgrounds and contexts. Thus, the scope of the review is not limited to studies of students according to context (such as school/home, developed/developing nations). However, adult participants and students with special needs were excluded as they are distinct from mainstream school students in terms of autonomy, fields and agency.

4. Used Bourdieu's constructs to conceptualise students' technology practice. This excluded a small number of studies that used a Bourdieu's constructs to measure generic aspects of social class (e.g., parental occupation, number books in the home) as a comparative analysis with students' technology skills or practices.

Table 1 provides an overview of the application of Bourdieu's theoretical constructs in the 16 studies. The application of Bourdieu's theoretical constructs in the study methodology, findings and discussion were reviewed for each study. Specifically, Table 1 outlines how each construct (field, habitus and capital) is used to conceptualise technology practice in the empirical research.

Within the existing body of educational technology research drawing on Bourdieu's sociology, researchers have taken up the theoretical concepts in varying degrees. Seven of the 16 studies focused on a specific construct of the theory to explore a specific structure or relation, while nine studies applied varying combinations of or all of the constructs to depict a tapestry of understanding of students' technology practice. The following section provides a review of the 16 studies according to the theoretical constructs, followed by a discussion of the opportunities and limitations of the application of the theory to future empirical research of student technology practice.

Five studies used field to the investigate structures and conditions within students' homes and school fields, as well as the intersections between these fields as students move between school and home. While physical conditions of the field (e.g. access to technology in the home) are well documented, these five studies, as outlined in Table 1 , demonstrate the ability of the theory to investigate more subtle or hidden structures and conditions of the field. These studies explored embodied structures of fields such 
as students' position of power in the field in regards to technology practice in

comparison with parents (Johnson 2009a) and teachers (Johnson 2009c; Taylor 2005),

\section{Table 1 Application of Bourdieu's theoretical constructs to students' technology} practice

\begin{tabular}{|c|c|}
\hline Construct & Conceptualisation of technology practice \\
\hline Field & $\begin{array}{ll}\text { - } & \text { Material resources, opportunity costs and constraints (Robinson 2009) } \\
\text { - } & \text { Rules of technology use at school and home (Beckman, et al. 2014) } \\
\text { - } & \text { Culture of technology use (Johnson 2009a) } \\
\text { - } & \text { Positions in fields of technology practice (Johnson 2009a, 2009c; Taylor 2005) } \\
\text { - } & \text { Conditions, boundaries and intersections of school and technology internship } \\
\text { - } & \text { program fields (Taylor 2005) }\end{array}$ \\
\hline Habitus & $\begin{array}{l}\text { - } \begin{array}{r}\text { Dispositions toward particular technology practices such as: } \\
\circ \quad \text { learning, socialising or leisure (Beckman, et al. 2014) } \\
\text { communication or authoring (Bulfin and North 2007), } \\
\text { leisure, personal development, and personal expression (Johnson 2009a, } \\
\text { 2009b) } \\
\text { 'informational habitus' or orientation toward and taste for internet use } \\
\text { (Robinson 2009) and information-seeking channels (Robinson 2011, } \\
\text { 2014) } \\
\text { experimentation approach toward using new technologies (Johnson } \\
\text { 2009b; Kapitzke 2000) }\end{array} \\
\text { - } \quad \text { Disposition toward technology use based on family practices and family value of } \\
\text { technology practices for particular purposes (Kapitzke 2000; North, et al. 2008) } \\
\text { - Shared beliefs and practices with technology at school and home (Beckman, et } \\
\text { al. 2014) and in online fields (Johnson 2009a, 2009b) } \\
\text { Intersubjective configuration of social elements in the informal use of technology } \\
\text { for learning - 'relational habitus' (Underwood, Parker \& Stone 2013) } \\
\text { Experiences with technologies (past and present) internalised (Beckman et al. } \\
\text { 2014; Bulfin and North 2007) } \\
\text { Parents' orientations toward technology use for learning ('affinities of style') } \\
\text { (Hollingworth, et al. 2011) and beliefs about technology use and expertise } \\
\text { (Johnson 2009b) } \\
\text { Family social class conceptualised by parental occupation, geographic location } \\
\text { and technology practices (North et al. 2008) } \\
\text { Family background and future aspirations (Taylor 2005) }\end{array}$ \\
\hline $\begin{array}{l}\text { Economic } \\
\text { capital }\end{array}$ & $\begin{array}{l}\text { - Family economic capacity evidenced by possession of technologies (Kapitzke } \\
\text { 2000; Hollingworth, et al. 2011) and to access the internet in the home (Cranmer } \\
\text { 2006; Kapitzke 2000; Hollingworth, et al. 2011) }\end{array}$ \\
\hline Cultural capital & $\begin{array}{l}\text { - Computer attitudes, use and competencies (Tondeur, et al. 2011) } \\
\text { - Digital tastes and capacity acquire cultural capital at school (North, et al. 2007) } \\
\text { - Conversion of 'internet literacy' as cultural capital across fields (Taylor 2005) } \\
\text { - Capacity to negotiate cyber-relations (Johnson 2009a), navigate harms and risks } \\
\text { online (Hollingworth, et al. 2011) } \\
\text { - Involvement in techno-culture (Kapitzke 2000) } \\
\text { - Socialisation into technology practice by family and friends (Beckman, et al. } \\
\text { 2014) } \\
\text { - Family orientation toward education and technology (Cranmer 2006; } \\
\text { Hollingworth et al. 2011; Sutherland-Smith, et al. 2003) } \\
\text { Time invested into developing technological skills and knowledge (Beckman et } \\
\text { al. 2014) }\end{array}$ \\
\hline
\end{tabular}


- Networks of technological contacts and support including parents, siblings and others (Beckman, et al. 2014; Cranmer 2006; Johnson 2009a; Taylor 2005; Sutherland-Smith, et al. 2003)

- Opportunities to learn technological skills and knowledge at school from teachers (Johnson 2009c)

demonstrating how these relationships according to field can attribute to the agency a student experiences with their technology practice. Understanding the structures of students' home fields, including the differing digital opportunities afforded to students' in these spaces, can provide educational technology researchers with important details about school students' orientation towards technologies (habitus). For example, Robinson's (2009) analysis of interview data focused on field structures related to access. This study investigated both physical and embodied structures including physical access to technologies as well as structures that limited or provided opportunities for access and emotional cost of such opportunities. The findings of this research reveal differences in the ways that students' technology practice is structured within the home field. Students' home experiences become internalised (habitus) resulting in the internalisation of different senses of 'possible' and 'impossible' in relation to technology practice (Robinson 2009). These internalised dispositions are carried by the individual as they move between fields, with the potential to influence technology practice in other fields.

Four of these five studies explored students' transitions between fields, using the structures of the fields to understand tensions or alignments between fields and the associated influence on students' technology practices (Beckman, Bennett and Lockyer 2014; Johnson 2009a, 2009c; Taylor 2005). Focusing on students' negotiations between school and technological workplace fields, Taylor (2005) examined the conditions, boundaries and intersects of each social space. The analysis explored the selection process and positioning of females in less desirable positions within the internship technological field, and thus uncovered the ways that such field structures worked to limit the impact of the internship for the female students. As field is a social space (rather than physical), physical spaces such as home or school, can include multiple fields, such as online gaming fields, or field of technology use for educational purposes at home (Johnson 2009a, 2009c). The structures and conditions of two such fields may feature differing rules associated with accessing devices, time allowed to dedicate to such practices and positions of power. Thus, a study of field involves extensive investigation and analysis of the physical, social and 
cultural structures and conditions of the field, which may not always be clearly evident in the reporting of the study analysis (Beckman, et al. 2014).

Twelve of the 16 studies used habitus to explore children and young peoples' technology practices through a range of approaches detailed in Table 1. Habitus has been used to conceptualise the distinction between social classes and associated tastes for technology practice. Researchers have focused on practices and dispositions to apprehend a sense of an individuals' habitus and the broader social group. Investigations focusing on individuals' and groups of individuals' dispositions have examined students' digital practices, orientation toward technology use, value, digital taste, social learning and approach to experimentation with digital technologies for particular purposes (Beckman, et al. 2014; Johnson 2009b; Kapitzke 2000; Underwood, Parker and Stone 2013). For example, one study aimed to describe the shared habitus of eight teenage experts (Johnson 2009b). This shared habitus manifested as a result of a similar orientation towards investing large time periods engaged in technology use for leisure (capital), along with experimentation and absorption in the activity.

Other studies have explored habitus in relation to social class to explore digital inequalities. This work comparing technology practices between social groups has focused on examining and comparing collective inclinations towards technology practise, digital taste and future aspirations towards technology use (North, Snyder and Bulfin 2008; Taylor 2005; Robinson, 2009). For example, a study of young peoples' digital 'tastes' conceptualised habitus through an investigation of capital amongst students from different family background groups (parental occupation, geographic location and technology practices) (North, et al. 2008). The study found differences in young people's digital tastes based on social class arguing that technology practices were appropriated to a young persons' existing habitus.

Extending this line of inquiry, others have investigated young peoples' habitus through the fields in which they operate. These studies focus on collecting data to understand field structures that shape students' habitus including the culture of technology use within the family home and school, parents' beliefs about technology use and expertise (Beckman, et al. 2014; Bulfin \& North, 2007; Johnson 2009a, 
2009b). For example, an investigation of the technology practices of secondary students details the varied ways that students' technological habitus is shaped by their past and present experiences with technologies according to field (Beckman et al, 2014). Consideration of habitus and how it is developed and evolves in particular fields as individuals move between fields draws attention to possible tensions between students' technological habitus and the culture of technology use in particular fields, thus restricting the experiences for some students (Beckman, et al. 2014; Johnson 2009a).

The application of habitus in this body of work illustrates the diverse nature of schools students' experiences with and dispositions towards technologies for particular purposes. Evidencing the diversity of students' technology practice has implications for technology practice in formal education, as students' will likely engage with these experiences in different and perhaps unequal ways. Similarly, tensions or alignment may be highlighted in students' capital, where capital may be of differing value according to field.

Ten studies used capital to explore social circumstances, relationships, networks and skills and knowledge in relation to students' technology practice. Three from these 10 studies applied economic capital to analyse students' and their family's capacity to acquire digital technologies (Cranmer 2006; Hollingworth, Mansaray, Allen and Rose 2011; Kapitzke 2000). In these studies, economic capital acts as one proxy for socioeconomic status that allows researchers to compare students' technology practice according to social class. Cultural capital was the most commonly used construct adopted by nine of the 16 studies (Beckman, et al. 2014; Cranmer 2006; Hollingworth, et al. 2011; Johnson 2009a; Kapitzke 2000; North Snyder and Bulfin 2008, Sutherland-Smith, et al. 2003; Taylor 2005; Tondeur, et al. 2011). These studies conceptualised cultural capital in varying ways to explore the origins of students' technological knowledge, skills and tastes. For example, a study of young people explored how socialisation into particular technology practices by family and friends led to the development of particular technology related cultural capital (Beckman, et al. 2014). Cultural capital was also used to explore students' capacity to navigate, negotiate and convert capital as they move between fields. Six studies also explored students' technological contacts and supports and the associated opportunities to 
develop technological cultural capital (Beckman, et al. 2014; Cranmer 2006; Johnson 2009a, 2009c; Taylor 2005; Sutherland-Smith, et al. 2003).

Conceptualising technology related capital in these studies provides important detail for educational technology researchers and users of research about the resources and processes school students draw upon to engage with technologies. Further, the diversity in student access to technology related capitals reinforce the social nature of technology. Yet, a focus on capital accumulation in isolation can only uncover part of the picture of children and young people's technology practice.

A common criticism of Bourdieu's constructs is a deterministic perspective of practice (Jenkins 1992), where students seem predisposed to certain practices without any evidence of agency. Such conclusions may be particularly evident when considering habitus or capital alone. To apprehend details of agency where individuals are able to negotiate and transform technology practices and understanding of the intersect of capital, habitus and field is required. However, review of these studies demonstrates there is a tendency to isolate specific constructs, rather than adopting the construct as part of the theory of practice.

Four of the 16 studies demonstrated the relational nature of the constructs through exploration of habitus, capital and field (Beckman, et al. 2014; Johnson 2009a; Kapitzke 2000; Taylor 2005). For example, exploring the impact of a school-based technology internship program for girls, Taylor (2005) investigated details of secondary students' cultural capital through their involvement in technology culture and social capital through their networks of technological support in both school and technology related work fields. This data was collected and analysed alongside the constructs habitus (family experiences with technology) and future aspirations and field (position(s) in and across fields), also embedded in the study, conceptually, methodologically and analytically. Demonstrating the relational nature of aspects of technology practice (through the constructs) highlighted a number of subtle forms of exclusion within the program that was designed to facilitate female students' engagement in technology related work fields. This study demonstrated, not a lack of student agency, particularly for the female students, but rather highlighted the 
structures that limited these students' ability to exert their agency in technology related work fields.

Key to the theory of practice is the relational nature of the theoretical constructs that are intended to be considered collectively (Bourdieu and Wacquant 1992). A selective application of Bourdieu's theory of practice might be considered a misuse of the theoretical constructs (Bourdieu and Wacquant 1992; Grenfell 2009). However, Bourdieu himself described his theory of practice as "open concepts designed to guide empirical work" (Bourdieu 1990a, 107, emphasis in the original). Therefore, in the field of educational technology research, where theoretically informed research is modest, this paper argues that the field may benefit from a sociological framing, even if it initially constitutes taking up elements of theory rather than the whole.

\section{Conceptualising technology practice using Bourdieu's sociology}

The inaccessibility of Bourdieu's writing may be one reason for its modest adoption in educational research. Bourdieu's writing was made accessible to a broader audience with its translation into multiple languages including English only recently; and his language is often perceived as ambiguous (Jenkins 1992). But perhaps another reason for its modest adoption in educational technology research is that Bourdieu did not theorise or investigate digital technology practice in his work (Sterne 2003). However, as society changes and digital technologies become more pervasive, research has begun to apply the theory to contemporary technology practice.

In addition to the empirical studies reviewed above, a number of educational technology and sociological researchers (Ignatow and Robinson 2017; Kvasny and Truex 2000; Selwyn 2004) have conceptualised Bourdieu's constructs applied to technology practice. Selwyn (2004) used Bourdieu's sociology to demonstrate the messy reality of students' access and practices. Specifically, he explored digital inequity by identifying technological capital as an extension and a subset of Bourdieu's cultural, economic and social forms of capital. In so doing, he reframed perceptions of "have" and "have-not" students to consider the origin of their varied capital and value within educational contexts. In addition, others have conceptualised technology practice more broadly in society, but not related to students. Kvasny and Truex (2000) provided a condensed summary of Bourdieu's theory of practice as it 
relates to information technology in general, and Ignatow and Robinson (2017)

offered a review of empirical studies in social science research. While conceptualisations of technology practice in society may be useful to consider, we argue that primary and secondary school students' technology practice is distinct from other users of technology, particularly adults, in terms of autonomy, fields and agency.

Drawing on review of the above empirical studies and relevant conceptual work (Ignatow and Robinson 2017; Kvasny and Truex 2000; Selwyn 2004) the following conceptualisation of school students' technology practices (Table 2) was developed and refined through two doctoral studies (Apps 2015; Beckman 2015). Table 2 outlines technological manifestations of Bourdieu's field, habitus and capital. This expansion is by no means exhaustive, but is intended as a conceptual framework to inform empirical research into school students' technology practice; to frame technology practice as embedded in the field; and to move toward understanding students' practices with technology so that it may better inform their use for learning in schools.

This table shows that Bourdieu's sociology is an expansive toolkit. Application of the theoretical framework in empirical research would involve the investigation of the multiple fields in which individuals engage, and encompass many more participants than the individual central to investigation. In the case of studying school students' technology practice, an investigation using the theoretical framework above would include exploring students' practices at school and in a range of everyday life fields (both online and offline), and investigating the technology practices of students' friends, teachers, parents and siblings. While much of the literature has focused on students' backgrounds and practices outside of school, and their influence on students' school practices, it is also necessary to investigate the school field. A critical reflection of school fields, specifically their structure, culture and habitus, may allow for comparison between the individuals and the institution.

This research strategy is comprehensive but arduous, the logistics of which perhaps have limited the application of this theory in educational technology research to date. Another limitation of a Bourdieu's sociology is its preoccupation with class 
structures and its apparently deterministic perspective of cultural reproduction, particularly in relation to education. Arguably, the determinist view of human agency, where individuals are fated to endure the social position into which they were born, Table 2 A conceptual application of Bourdieu's theory of practice to school students' technology practice

\begin{tabular}{|c|c|}
\hline Construct & Technological manifestations for school students \\
\hline $\begin{array}{l}\text { Field } \\
\quad \text { Objectified }\end{array}$ & $\begin{array}{l}\text { - Technology resources available and accessible } \\
\text { - Location and distribution of technological resources } \\
\text { - Others' (e.g. family, friends, teachers) position(s) in field, dispositions } \\
\text { and technology experiences }\end{array}$ \\
\hline Embodied & $\begin{array}{l}\text { - Culture of technology use (including rules, others' perceptions and } \\
\text { practices) } \\
\text { - Position in the field in relation to technological capital } \\
\text { - Being attuned to the "rules of the game" of technology practices }\end{array}$ \\
\hline Habitus & $\begin{array}{l}\text { - Circumstances or background, including family structure and parents' } \\
\text { and siblings' occupations } \\
\text { - Personal disposition toward technology } \\
\text { - Past and present experiences with technology } \\
\text { - Shared beliefs and accepted practices with technologies (doxa) } \\
\text { - Personal beliefs and perceptions about the value of technologies } \\
\text { Possibility of success or profit (interest) as a result of technology } \\
\text { practices }\end{array}$ \\
\hline Economic capital & $\begin{array}{l}\text { - Family economic capacity to purchase technology hardware and } \\
\text { software } \\
\text { - Technology resources available }\end{array}$ \\
\hline $\begin{array}{c}\text { Cultural capital } \\
\text { Embodied }\end{array}$ & $\begin{array}{l}\text { - Investing time into self improvement of technology skills, knowledge } \\
\text { and competencies in the form of informal learning } \\
\text { - Participation in technology education and training - both formal } \\
\text { credentialized and informal non-credentialized }\end{array}$ \\
\hline Objectified & - Appropriation of technocultural goods into embodied cultural capital \\
\hline Institutionalised & - Formal technology training/courses \\
\hline Social capital & $\begin{array}{l}\text { - Networks of 'technological contacts' and support. These can be: } \\
-\quad \text { Face-to-face: family, friends, teachers, others } \\
\text { - Remote: online help facilities, online forums }\end{array}$ \\
\hline
\end{tabular}

Note: Terms directly quoted from Selwyn $(2004,355)$ are indicated in italics.

has little to offer educational research (Jenkins 1992). However, the review of the studies above illustrate the opposite, drawing attention to the intersection of Bourdieu's theoretical constructs, habitus, capital and field, to explain the role of 
agency beyond objective structures upon an individuals' technology practice (Beckman, et al. 2014; Johnson 2009a; Kapitzke 2000; Taylor 2005).

Further, as habitus is shaped through experiences, including those at school, which is a significant field in the structuring of students' habitus. Schools need not be a field only of reproduction, but also have the potential to be a field of transformation through researchers and educators embracing an awareness of and critical reflection on the structures and systems that may perpetuate social and cultural inequalities (Mills 2008). This means that exploration of school fields may highlight structures or practices, such as school rules or lesson design, which reproduce or transform students' technology practices. Ultimately, conceptualising the school field in this way may lead to changes in such systems and practices and student learning with technologies.

Bourdieu's theoretical constructs were born out of his empirical research, and thus were intended to be methodological tools with which to study social phenomena (Grenfell 2012). This review of empirical research reveals there is certainly scope, moreover a need, for sociologically informed research of this kind in the field of educational technology. The investigation of student technology practice, guided by Bourdieu's concepts of field, habitus and capital, can contribute to understanding students' general practices, their practices for learning, and the relationship between the school and everyday life fields. We offer this conceptualisation of technology practice through Bourdieu's theoretical constructs and invite its application to the investigation of students' technology practice so that it can be critiqued and further developed.

\section{Conclusion}

In this paper, we have reviewed the empirical research of 16 studies using Bourdieu's theory of practice to investigate school students' technology practice. These studies have contributed to the field of educational technology research by highlighting that technologies are social tools, and that students' practices are complex and influenced by a broad range of social and cultural factors. The issues raised in this paper present challenges for educational technology researchers in understanding the complex language and adopting an arduous methodology. Yet the application of Bourdieu's 
theoretical constructs offers a fresh approach to investigating technology practice across students' lives in a rigorous manner and providing a common conceptual measure.

Disclosure statement

No potential conflict of interest was reported by the authors.

\section{ORCID}

Karley Beckman http://orcid.org/0000-0002-3435-5083

Tiffani Apps http://orcid.org/0000-0002-7688-176X

Sue Bennett http://orcid.org/0000-0001-9607-6285

Lori Lockyer http://orcid.org/0000-0003-1517-2342 


\section{References}

Apps, Tiffani. 2015. ICT literacy and the digital divide: Understanding primary students' ICT practices and possibilities (Unpublished doctoral dissertation). Wollongong: University of Wollongong.

Australian Curriculum, Assessment and Reporting Authority (ACARA). 2015. "National assessment program ICT literacy: Years 6 and 10 report 2014". Accessed 31 June 2016. http://www.nap.edu.au/_resources/D15_8761_NAPICT_2014_Public_Report_Final.pdf

Beckman, Karley. 2015. Secondary school students' technology practices in their everyday lives and at school (Unpublished doctoral dissertation). Wollongong: University of Wollongong.

Beckman, Karley, Sue Bennett, and Lori Lockyer. 2014. "Understanding students' use and value of technology for learning." Learning, Media and Technology 39(3): 346-367. doi:10.1080/17439884.2013.878353.

Bennett, Sue, and Martin Oliver. 2011. "Talking back to theory: The missed opportunities in learning technology research." Research in Learning Technology 19(3): 179-189. doi:10.1080/21567069.2011.624997.

Bok, Jessica. 2010. "The capacity to aspire to higher education: 'It's like making them do a play without a script'." Critical Studies in Education 51(2): 163-178. doi:10.1080/17508481003731042.

Bourdieu, Pierre. 1977. Outline of a Theory of Practice. London: Cambridge University Press.

Bourdieu, Pierre. 1984. Distinction. London: Routledge.

Bourdieu, Pierre. 1986. “The forms of capital.” In Handbook of theory and research for the sociology of education, edited by J. Richardson, 241-256. Connecticut: Greenwood Press.

Bourdieu, Pierre. 1990a. In other words: Essays towards a reflexive sociology. Cambridge: Polity Press.

Bourdieu, Pierre. 1990b. The logic of practice. Cambridge: Polity.

Bourdieu, Pierre. 2005. The social structures of the economy. Cambridge: Polity Press.

Bourdieu, Pierre, and Loic JD Wacquant. 1989. "Towards a reflexive sociology: A workshop with Pierre Bourdieu." Sociological theory 7(1): 26-63.

Bourdieu, Pierre, and Loic JD Wacquant. 1992. An invitation to reflexive sociology. Chicago: University of Chicago Press. 
Bulfin, Scott, and Sue North. 2007. "Negotiating digital literacy practices across school and home: Case studies of young people in Australia." Language and Education 21(3): 247-263. doi:10.2167/le750.0.

Cranmer, Sue. 2006. "Children and young people's uses of the Internet for homework." Learning, Media and Technology 31(3): 301-315. doi:10.1080/17439880600893358

Cuban, Larry. 2001. Oversold and underused. Cambridge: Harvard University Press.

DiMaggio, Paul. 1982. "Cultural capital and school success: The impact of status culture participation on the grades of US high school students." American Sociological Review 47(2): 189-201.

Dumais, Susan A. 2002. "Cultural capital, gender, and school success: The role of habitus." Sociology of Education 75(1): 44-68.

Erstad, Ola. 2012. "The learning lives of digital youth—-beyond the formal and informal." Oxford Review of Education 38(1): 25-43. doi:10.1080/03054985.2011.577940.

Everett, Jeffery. 2002. "Organizational research and the praxeology of Pierre Bourdieu." Organizational Research Methods 5(1): 56-80. doi:10.1177/1094428102051005.

Fenwick, Tara, Richard Edwards, and Peter Sawchuk. 2015. Emerging approaches to educational research: Tracing the socio-material. Routledge.

Gaddis, S. Michael. 2013. "The influence of habitus in the relationship between cultural capital and academic achievement." Social science research 42(1): 113.

Grenfell, Michael. 2009. "Applying Bourdieu's field theory: the case of social capital and education." Education, Knowledge \& Economy 3(1): 17-34. doi:10.1080/17496890902786812.

Grenfell, Michael. 2012. Pierre Bourdieu: Key concepts (2nd ed.). Durham: Acumen. Grenfell, Michael, and David James. 1998. Bourdieu \& Education: Acts of Practical Theory. Florence: Taylor \& Francis.

Hollingworth, Sumi, Ayo Mansaray, Kim Allen, and Anthea Rose. 2011. "Parents' perspectives on technology and children's learning in the home: social class and the role of the habitus." Journal of Computer Assisted Learning 27(4): 347-360. doi:10.1111/j.1365-2729.2011.00431.x. 
Ignatow, Gabe, and Laura Robinson. 2017. "Pierre Bourdieu: theorizing the digital." Information, Communication \& Society, 20(7): 950-966. doi:

10.1080/1369118X.2017.1301519.

Jenkins, Richard. 1992. Pierre Bourdieu. London: Routledge.

Johnson, Nicola F. 2009a. "Cyber-relations in the Field of Home Computer Use for Leisure: Bourdieu and teenage technological experts." E-Learning and Digital Media 6(2): 187-197. doi:10.2304/elea.2009.6.2.187.

Johnson, Nicola F. 2009b. "Generational differences in beliefs about technological expertise." New Zealand Journal of Educational Studies 44(1): 31-45.

Johnson, Nicola F. 2009c. "Teenage Technological Experts' Views of Schooling." The Australian Educational Researcher 36(1): 59-72.

Kapitzke, Cushla. 2000. "Information technology as cultural capital: Shifting the boundaries of power." Education and Information Technologies 5(1): 49-62.

Kerr, Stephen T. 1996. "Toward a sociology of educational technology." In Handbook of research on educational communications and technology: A project of the association for educational communications and technology edited by D. Jonassen, 113-142. London: Lawrence Erlbaum Associates Publishers.

Kvasny, Lynette, and Duane Truex. 2000. "Information technology and the cultural reproduction of social order: A research paradigm." In Organizational and social perspectives on information technology, edited by R. Baskerville, J. Stage and J. DeGross, 277-293. Springer US.

Latour, Bruno. 2005. Reassembling the social: an introduction to Actor-NetworkTheory. Oxford: Oxford University Press.

McNamara Horvat, Erin, and James Earl Davis. 2011. "Schools as sites for transformation: Exploring the contribution of habitus." Youth \& Society 43(1): 142-170.

Mills, Carmen. 2008. "Reproduction and transformation of inequalities in schooling: The transformative potential of the theoretical constructs of Bourdieu." British Journal of Sociology of Education 29(1): 79-89. doi:10.1080/01425690701737481.

Mills, Carmen, and Trevor Gale. 2007. "Researching social inequalities in education: Towards a Bourdieuian methodology." International Journal of Qualitative Studies in Education 20(4): 433-447. doi: 10.1080/09518390601176523. 
Mills, Carmen, and Trevor Gale. 2010. Schooling in disadvantaged communities. London: Springer.

Nash, Roy. 1990. "Bourdieu on education and social and cultural reproduction." British Journal of Sociology of Education 11(4): 431-447.m doi:10.1080/0142569900110405.

Nicolini, Davide. 2012. Practice Theory, Work, and Organization: An Introduction. OUP Oxford.

North, Sue, Ilana Snyder, and Scott Bulfin. 2008. " Digital tastes: Social class and young people's technology use." Information, communication \& society 11(7): 895-911. doi:10.1080/13691180802109006.

Organisation for Economic Co-operation and Development (OECD). 2010. Are the new millennium learners making the grade? Technology use and educational performance in PISA. Educational Research and Innovation. Accessed 23 June 2016.

http://www.oecd.org/edu/ceri/educationalresearchandinnovationarethenewmill enniumlearnersmakingthegradetechnologyuseandeducationalperformanceinpis a2006.htm

Organisation for Economic Co-operation and Development (OECD). 2011. PISA 2009 results: Students on line. Accessed 23 June 2016. http://dx.doi.org/10.1787/9789264112995-en

Oliver, Martin. 2013. "Learning technology: Theorising the tools we study." British Journal of Educational Technology 44(1): 31-43. doi:10.1111/j.14678535.2011.01283.x.

Oliver, Martin. 2016. "What Is Technology?” The Wiley Handbook of Learning Technology 1: 35 .

Reay, Diane. 2004. "'It's all becoming a habitus': Beyond the habitual use of habitus in educational research." British journal of sociology of education 25(4): 431444. doi:10.1080/0142569042000236934.

Robbins, Derek. 2004. "The transcultural transferability of Bourdieu's sociology of education." British Journal of Sociology of Education 25(4): 415-430. doi:10.1080/0142569042000236925.

Robinson, Laura. 2009. "A taste for the necessary: A Bourdieuian approach to digital inequality." Information, Communication \& Society 12(4): 488-507. doi:10.1080/13691180902857678. 
Robinson, Laura. 2011. "Information-channel preferences and informationopportunity structures." Information, Communication \& Society 14(4): 472494.

Robinson, Laura. 2014. "Endowed, Entrepreneurial, and Empowered-Strivers: Doing a lot with a lot, doing a lot with a little." Information, Communication \& Society 17(5): 521-536. doi:10.1080/1369118X.2013.770049.

Schubert, Daniel. 2012. "Suffering/symbolic violence.” In Pierre Bourdieu: Key concepts, edited by Michael Grenfell, 183-198. Routledge.

Selwyn, Neil. 2004. "Reconsidering political and popular understandings of the digital divide." New Media \& Society 6(3): 341-362. doi:10.1177/1461444804042519.

Selwyn, Neil. 2010. "Looking beyond learning: Notes towards the critical study of educational technology." Journal of Computer Assisted Learning 26(1): 65-73. doi:10.1111/j.1365-2729.2009.00338.x.

Selwyn, Neil. 2012. "Making sense of young people, education and digital technology: The role of sociological theory." Oxford Review of Education 38(1): 81-96. doi:10.1080/03054985.2011.577949.

Sterne, Jonathan. 2003. "Bourdieu, technique and technology." Cultural Studies 17(34): 367-389.

Sutherland-Smith, Wendy, Ilana Snyder, and Lawrence Angus. 2003. "The digital divide: Differences in computer use between home and school in low socioeconomic households." Educational Studies in Language and Literature 3(12): 5-19. doi:10.1023/A:1024523503078.

Swartz, David. 1997. Culture and power: The sociology of Pierre Bourdieu. London: University of Chicago Press.

Taylor, Alison. 2005. "Finding the future that fits." Gender and Education 17(2): 165187. doi:10.1080/0954025042000301447.

Tondeur, Jo, Ilse Sinnaeve, Mieke Van Houtte, and Johan van Braak. 2011. "ICT as cultural capital: The relationship between socioeconomic status and the computer-use profile of young people." New Media \& Society 13(1): 151-168. doi:10.1177/1461444810369245.

Underwood, Charles, Leann Parker, and Lynda Stone. 2013. "Getting it together: relational habitus in the emergence of digital literacies." Learning, Media and Technology 38(4): 478-494. doi:10.1080/17439884.2013.770403. 
Wacquant, Loïc. 1998. "Pierre Bourdieu." In Key sociological thinkers, edited by R. Stones, 215-229. London: Macmillan Press.

Webb, Jen, Tony Schirato, and Geoff Danaher. 2002. Understanding Bourdieu. Sage. 